\title{
Can Epicardial Adipose Tissue be Defined as an Early Marker of Treatment Decisions of Subclinical Hypothyroidism in Childhood?
}

Gaye Aşik ${ }^{1}$, Ayça Törel Ergür ${ }^{2 *}$ and Cihat Şanli ${ }^{3}$ ${ }^{1}$ Department of Pediatrics, Kurıkkale University Faculty of Medicine, Turkey

${ }^{2}$ Department of Pediatric Endocrinology, Ufuk University Faculty of Medicine, Turkey

${ }^{3}$ Department of Pediatric Cardiology, Kırıkkale University Faculty of Medicine, Turkey

*Corresponding author: Ayça Törel Ergür,

Department of Pediatric Endocrinology, Ufuk University Faculty of Medicine, Ankara, Turkey

Received: J anuary 18, 2021; Accepted: February 05, 2021; Published: February 12, 2021

\begin{abstract}
Introduction and Aim: Childhood overt hypothyroidism is a chronic disease that affect many system adversely and requires treatment. However, Subclinical Hypothyroidism (SH), defined obvious cases, impacts on other systems are unknown and there is no common approach to be treated. Moreover, SH may continue for many years, before they become overt hypothyroidism. Cardiovascular System (CVS) is one of the host system, which hypothyroidism adversely affects. Epicardial Adipose Tissue thickness (EAT) is known to be an important marker in terms of the cardiovascular risks. We aimed to determine the effects on CVS in children with SH.
\end{abstract}

Material and Methods: The study included were 100 cases, which are 1-18 years had categorized in two groups; control group (50 children), who had no signs of thyroidal dysfunction and case group (50 children) who had diagnosed with $\mathrm{SH}$, are recruited in the study. $\mathrm{SH}$ was diagnosed according to the slightly higher TSH than the upper limit (4.2M/L), normal free T4 and T3 levels. Medical Treatment (LT4) was decided according to the levels of TSH, ST3, ST4 and clinical status. EAT was determined by transthoracic echocardiographic measurements in millimeters. The $\mathrm{SH}$ cases were classified into two groups in terms of medical treatment. EAT thickness was measured in patients with treated group $(\mathrm{SH} 1)$ and non-treated group $(\mathrm{SH} 2)$ at admission (EATO) and at 6. months (EAT 6).

Results: Epicardial adipose tissue thickness was significantly higher in $\mathrm{SH}$ children, than the children without thyroid dysfunction. The mean value of the EAT in control group was $2,11 \pm 0,52 \mathrm{~mm}$. Mean of EAT0 was $4,08 \pm 1,41$ in group SH1, mean of EAT0 was $4,31 \pm 1,09 \mathrm{~mm}$ in group SH2. In addition, mean of EAT6 was $3.65 \pm 1,27 \mathrm{~mm}$ in group SH1 and mean of EAT6 was 4,16 $\pm 1,10$ in group SH2. Although there were a decrease in both group $\mathrm{SH} 1$ and $\mathrm{SH} 2$, at EAT6 compared to the EATO, and this decrease was more significant in group $\mathrm{SH} 1$.

Discussion: This study suggests that subclinical hypothyroidism effects adversly the cardiovascular system in children before hypothyroidism become overt. In future this data may be marker at the begining of LT4 treatment in children with $\mathrm{SH}$.

Keywords: Childhood subclinical hypothyroidism; Epicardial adipose tissue thickness; Epicardial fat tissue thickness

\section{Introduction and Aim}

Thyroid hormones have great effect on growth, puberty and human metabolism [1]. Childhood overt hypothyroidism is a chronic disease that affects many systems adversely and requires treatment. However, effects of Subclinical Hypothyroidism (SH), which is defined by obvious cases with higher TSH and normal free T4 (fT4) on other systems are unknown and there is no common approach to be treated [2]. For that reason, SH can be defined as "devious danger of childhood". Moreover, SH may continue for many years, before they become overt hypothyroidism.

Prevalence of subclinical hypothyroidism is reported about $2 \%$ in children, prevalence of $\mathrm{SH}$ in general population is reported about $1-12.4 \%$ in some studies [3-6]. However, screening of thyroidal function, which becomes a part of routine laboratory examinations, showed higher than expected prevalence of $\mathrm{SH}$ in patients with family history of thyroidal disease or presence of goiter [4-6]. As a result, that disease with great importance clinically is defined as the tip of the iceberg.

Clinical findings in patients with subclinical hypothyroidism could varied from asymptomatic to typical hypothyroidism [7]. Goiter, decline in school success, especially in maths, growth failure, low height and weight percentiles, or loss of percentile of height/weight refractory iron deficiency anemia, dyslipidemia (hypocholesteremia) could be presented in that cases. Symptoms like
Annals Thyroid Res - Volume 7 Issue 1 - 2021

Submit your Manuscript | www.austinpublishing group.com

Ayça Törel Ergür et al. (C) All rights are reserved
Citation: Aşik G, Ergür AT and Şanli C. Can Epicardial Adipose Tissue be Defined as an Early Marker of Treatment Decisions of Subclinical Hypothyroidism in Childhood?. Annals Thyroid Res. 2021; 7(1): 301-305. 
negativism, panic attack, depression, attention deficiency in children foreshow the $\mathrm{SH}$ [8]. However, laboratory findings in $\mathrm{SH}$ are also often overlooked. The treatment decision varies greatly and there is no common approach to treatment. For this reason, it is necessary to clarify the criteria for initiation of treatment. This need requires further research in this regard.

Cardiovascular System (CVS) is the one of the main system, which hypothyroidism adversely affects. It is well known that EAT is an important marker for cardiovascular risks [9]. Although EAT has some protective effects on cardiovascular risk, such as metabolic and mechanic status; increased EAT levels are linked with negative outcome. There is a casual relationship between EAT and various diseases, such as obesity, insulin resistance, hypertension, atherosclerosis and metabolic syndrome. EAT is a good predictor of visceral lipidosis than waist circumference, because EAT is not affected by skin and muscle, like waist circumference.

In that study, we aimed to evaluate the EAT in children with $\mathrm{SH}$ and observe the effect of SH on EAT in children. This study is the first study which investigates that relationship.

\section{Material and Methods}

100 cases whose age ranged between 1 to 18 years are included in this study; 50 cases were diagnosed $\mathrm{SH}$ (SH group), 50 cases, who had no signs of thyroidal dysfunction were defined as healthy control group (control group). SH was diagnosed in children who had slightly higher TSH than the upper limit $(4.2 \mathrm{M} / \mathrm{L}), \mathrm{fT} 4$ and fT3 within the normal limit. Control group were defined as children who applied to pediatric endocrinology clinic with the symptoms of fatigue, sleep disorder and nervousness and whose routine laboratory examinations were normal. Obese children, children with dyslipidemia and/ or tendency to have dyslipidemia, malignancy, diabetes, chronic diseases like cardiovascular, metabolic syndrome and hepatic, renal disorders; children who use drug regularly are excluded from the study. After having a detailed medical information about children; antropometric (chronological age, bone age, weight, height, BMI), physical examination and thyroid examination (WHO UNICEF) of all SH-diagnosed cases were performed. Thyroid function tests (fT3, fT4, TSH), thyroid antibodies, spot urine iodine, hemogram, ferritin, zinc, vitamin D (25OHD), vitamin B12 and folate were analyzed to evaluate the thyroidal dysfunction. Serum lipid and homocysteine levels were analyzed to exclude the coronary artery disease. Decision of medical treatment (LT4) is based on both symptoms, clinical and laboratory findings of $\mathrm{SH}$ cases. Cases who received medical treatment were defined as group $\mathrm{SH} 1$, cases who received conventional treatment were defined as group SH2. L-T4 treatment is started with the low dose of $2 \mu \mathrm{g} / \mathrm{kg} /$ day and dose was followed up with TSH and fT4 measurement in every four weeks. SH2 cases who had diagnosed with apparent hypothyroidism in the follow-up period, had excluded from the study. Patient whose TSH level $>20 \mathrm{mIU} / \mathrm{L}$ had excluded from the study. With the reason to determine the underlying cause of $\mathrm{SH}$, patients were screened for thyroid autoantibodies, thyroid USG and spot urine iodine.

Epicardial adipose tissue thickness ratios were assessed by same cardiologist using transthoracic echocardiography using 2-D and M-Mode techniques on a General Electric Vivid 7 device with 2.5-
3.5 MHz transducer in the left lateral decubitus position after resting for 10 minutes. In two-dimensional echocardiographic examination, EAT was measured at the end of parasternal long-axis diastole, from the $1 / 3$ section of the ventricular basal, which is adjacent to the right ventricular free wall at vertical, horizontal and cross-sectional sections. EATs of all SH group patients were assessed at 0, (EAT 0) and 6 months (EAT 6). EAT 0 was measured for all control group patients.

\section{Statistical analysis}

Statistical analysis of data was performed in SPSS 23.0 (Statistical Package for the Social Science) programme. Descriptive statistics were presented as number and percentage for categorical variables; mean and standard deviation for numeric variables. ANOVA test and Wilcoxon test were used to compare multiple independent groups if normality of values were confirmed; Kruskal Wallis test was used if normality of values were not confirmed. Tukey and chisquare and $\mathrm{T}$ test were used to comparison of sub groups for numeric and categorical variables, respectively. To determine the statistical significance level, 95\% confidence interval and $p$ value $<0.05$ were considered significant.

This study was approved by the Institutional Review Board (IRB) of Kırıkkale University Faculty of Medicine, Kırıkkale, Turkey under IRB number 17/12 (date: 21/06/2017). All patients and their parents were provided written informed consent and assent was obtained from all study participants before participating.

\section{Results}

There were no significant differences between $\mathrm{SH}$ group and control group, in terms of HDL, LDL, Triglyceride, Total Cholesterol, Hemoglobin (Hb), White Blood Count (WBC), Platelet (PLT), Vitamin D (25OHD), ferritin (Fe), vitamin B12 and folate ( $\mathrm{p}>0.05)$. Mean homocysteine levels of SH group was within normal limits, there was no statistically difference between SH group and normal population $(\mathrm{p}>0.05)$

Although there were statistically significant differences between $\mathrm{SH}$ and control group in TSH and fT3 values $(\mathrm{p}<0.05)$, there was no significant difference among groups in fT4 values $(\mathrm{p}>0.05)$ Mean EAT0 in children with control, $\mathrm{SH} 1$ and $\mathrm{SH} 2$ group were $2.11 \pm 0.52 \mathrm{~mm}, 4.08 \pm 1.41 \mathrm{~mm}$ and $4.31 \pm 1.09$, respectively. There was a statistically significant difference between $\mathrm{SH}$ and control group's EAT measurements $(\mathrm{p}<0.05)$.

Mean EAT values of pubertal children with control and $\mathrm{SH}$ group ( $2.51 \pm 0.36 ; 5.28 \pm 0.73$, respectively) were significantly higher than EAT values of prepubertal children with control and $\mathrm{SH}$ group $(1.81 \pm 0.42 ; 3.40 \pm 1.10$, respectively) $(\mathrm{p}<0.005)$. EAT is increased with the age and BMI percentile $(\mathrm{p}<0.005 ; \mathrm{p}<0.005$, respectively). EAT is increased with the presence of positive anti-TPO and anti-TG values in children with SH group ( $\mathrm{p}<0.005)$. There was no statistically significant relationship between spot urine iodine and EAT in SH group ( $>0.05)$. EAT is increased with increased heterogeneity of thyroid parenchyma $(\mathrm{p}<0.05)$.

EAT6 measurements were lower than EAT0 in SH2 and SH1 groups, however that relationship was more predominant in $\mathrm{SH} 1$ group. 


\section{Discussion}

With the widespread use of screening tests in recent years, the incidence is increasing in childhood and adolescents. But the consensus among endocrinologists is still unclear for the treatment of the disease. If childhood SH is not treated, it is highly likely to go hypothyroidism. Especially in untreated cases in the first year of life, obvious hypothyroidism and consequent growth retardation and the possibility of developing neurocognitive dysfunction may become a potential and insidious threat to children in the era of development. For this reason, it is very important to know this clinical entity well, to take precautions early and to minimize the loss.

Subclinical hypothyroidism is higher in girls than in boys [12]. In our study, $\mathrm{SH}$ group consisted of 26 (52\%) of the patients and 24 (48\%) of the males. The iodine status is also very important in the etiology of SH. The incidence of iodine deficiency in our study was $16 \%$.

Measuring serum TSH concentration is the most sensitive test to show thyroid function $[13,14]$. However, the difficulty in defining normal TSH value may differ from the clinician in establishing $\mathrm{SH}$. Until the diagnosis of $\mathrm{SH}$, treatment is a controversial clinical entity, and no precise criteria have yet been established for treatment L-T4 therapy in patients with TSH $<10 \mathrm{mIU} / 1$ in children without symptoms is highly controversial and there are limited studies in this issue [15]. In our study, mean TSH level of SH patients treated was $6.56 \pm 3,02(\mathrm{mIU} / \mathrm{mL})$ and TSH level of non-treated group (SH2) was $5.68 \pm 1.05(\mathrm{mIU} / \mathrm{mL})$. Likewise, the mean $\mathrm{fT} 4$ value of SH1 was $1.24 \pm 0.16(\mathrm{ng} / \mathrm{mL})$ and the sT3 value was $4.45 \pm 0.66(\mathrm{ng} / \mathrm{mL})$. Mean fT4 value of the non-treated group was $1.26 \pm 0.13(\mathrm{mIU} / \mathrm{mL})$ and fT3 value was $4.22 \pm 0.63(\mathrm{ng} / \mathrm{mL})$.

Although subclinical hypothyroidism is not shown clinical findings, many studies have shown that $\mathrm{SH}$ causes abnormalities in lipid metabolism and increase in serum cholesterol levels parallel to serum TSH levels [16]. In our study, we excluded cases with dyslipidemia in particular, so we aimed to investigate the effect of $\mathrm{SH}$ on EAT without the presence of dyslipidemia.

The incidence of coronary heart disease and the increase in mortality in SH cases were found to be correlated with TSH> $7 \mathrm{mIU} / \mathrm{L}$ [17]. It is known that L-T4 treatment in children and adults alleviates apparent hypothyroid cardiac function [18]. In the literature, there are only two studies showing cardiac functions in childhood group $\mathrm{SH}$ cases. However, two of these studies include cases of Down syndrome and obesity. Toscano et al. studied left ventricle funcitons of 16 patients with Down's syndrome (mean age 65.5 months, mean TSH $7.8 \mathrm{mIU} / \mathrm{L}$ ), and 25 healthy euthyroid children (mean age 70.3 months, mean TSH 3,2 mIU / L), and they did not find any significant difference. However, this result of studying is attributed to the early ages of the cases and the short follow-up period [19]. In another study comparing cardiac functions in obese $\mathrm{SH}$ cases and euthyroid healthy children, the left ventricular function of the obese SH group was significantly lower than the control group [20]. Left ventricular functions were found to be significantly lower in $\mathrm{SH}$ cases in another study where left ventricular function was assessed. There was a significant increase in left ventricular systolic and diastolic function after 6 months of L-T4 therapy [16]. In the literature, there is not efficient information about the effect of L-T4 treatment on cardiac function in children with isolated $\mathrm{SH}$.

Epicardial adipose tissue thickness is another important marker in terms of cardiovascular risks $[21,22]$. There are some studies in the adulthood which explore the relationship between SH and EAT, and also some studies take place in the literature which examine the relationship between EAT and L-T4 treatment in SH [21,23-27]. However there are very limited studies in childhood which explore the relationship between $\mathrm{SH}$ and EAT, and there is no study in childhood which examine the relationship between EAT and L-T4 treatment in SH. Asik G. et al. studied a total 50 children $(25 \mathrm{SH}$ and 25 without thyroid dysfunction), they found that EAT was significantly higher than children without thyroid dysfunction. Likewise, the EAT of SH cases were found to be significantly higher than the control group [28]. Farghaly et al. Studied a total of 64 children (32 SH and 32 without thyroid dysfunction), of which all of the $\mathrm{SH}$ group consisted of cases due to autoimmune thyroiditis, they found that the EAT of $\mathrm{SH}$ cases were found to be significantly higher than the control group [29]. In our study, we observed that mean EAT0 of not treated $\mathrm{SH}$ cases was $4,31 \pm 1,09 \mathrm{~mm}$ and the mean EAT0 thickness of treated SHs (SH1) was determined as $4,08 \pm 1,41 \mathrm{~mm}$.

Myocardial Performance Index (MPI) is an easy method for evaluating systolic and diastolic cardiac function [30]. In a study by Yazici et al, which compares SH events and control group in adults at 2014, MPI value pf SH group was found to be significantly lower than the control group and it was shown that the decrease in MPI with L-T4 treatment was reversible. In the same study, the EAT thickness was found to be higher in the SH group than in the control group, and a 6-month L-T4 treatment reduced the EAT thickness [31]. We also found that the decrease in EAT in the group who receive L-T4 therapy was more prominent. In addition, we found that the mean EAT6 thickness in the SH1 group was $3.65 \pm 1.27 \mathrm{~mm}$, while the EAT6 thickness in the SH2 group was $4.16 \pm 1.10 \mathrm{~mm}$. Statistically significant decrease was detected in EAT6 compared to EAT0, and the decrease in EAT in SH1 group was statistically more significant $(\mathrm{p}<0.005)$. The reduction in the EAT thickness of the SH2 group was thought to be associated with conventional therapy. The SH1 group was thought to be more effective for the $\mathrm{SH} 2$ group at the 6th month for the L-T4 treatment.

In our study, statistically significant relationship was found between the values of EATs in SH group and age. The EAT thickness increased with age $(p<0.05)$. This may be related to the increase in visceral adipose tissue as age increases. Significant correlations were found between EAT and BMI in previous adult studies [32]. There are contradictory publications in the literature regarding the relationship between BMI and EAT. Vertical measurements of the EAT with the ECO have been reported previously as an independent indicator of visceral adipose tissue, but as a weak indication of the degree of obesity measured by BMI [25]. Ahn et al. found that there was a significant association among the groups with the EAT vertical measurement above and below $3 \mathrm{~mm}$ in terms of BMI [32]. In our study, a statistically significant relationship was found between $\mathrm{SH}$ and the control group in terms of BMI and EAT thickness. As the BMI level increases, the EAT thickness also increases $(\mathrm{P}<0.05)$. Ergür et al found a statistically significant increase in body adipose 
percentage (Fat mass) was found when bioelectrical impedance and body composition were evaluated in children with SH (especially adolescents) study. ${ }^{33)}$ In $\mathrm{SH}$ cases, this result may be the cause of the increase in EAT. These two findings are the earliest developing parameters and may be effective for future treatment decisions.

The rate of apparent hypothyroidism was higher in patients with high thyroid autoantibody titers and also have hypoecogenic thyroid ultrasonography [3]. If the anti-TPO antibody is not positive in a case with $\mathrm{SH}$, the rate of progression to having an apparent hypothyroid is determined as $2.6 \%$, whereas it is $4.3 \%$ when antiTPO is positive [34]. Scott et al claim that the presence of goiter and anti-Tg positivity at the time of admission, and the increase in antiTPO antibody and TSH levels in the follow-up were two predictive markers of developing apparent hypothyroid development in these cases [35]. Radetti et al stated that increased thyroid volume and anti-thyroid antibodies were found to be associated with a higher risk of developing $\mathrm{SH}$ in these patients with impaired thyroid function [7]. In our study, a statistically significant relationship was found between the anti-TPO and Anti-Tg groups in the SH group. The positive value of Anti TPO and Anti Tg increase the EAT thickness $(\mathrm{P}<0.05)$. A statistically significant correlation was found between the EAT values and the thyroid parenchyma size in the SH group. There was an inverse proportion between thyroid parenchyma measure and EAT. $(\mathrm{P}<0.05)$. These data suggest that thyroid antigens and thyroid parenchymal may be effective in predicting the increase in the EAT thickness.

In conclusion, in our study, epicardial adipose tissue thickness was significantly higher in children with subclinical hypothyroidism than children without thyroid dysfunction. This study suggests that adverse effects on the cardiovascular system have begun in children with $\mathrm{SH}$ without developing apparent hypothyroidism. The significant value of our study is that EAT measurements can provide a clear criterion, especially in the presence of highly controversial L-T4 treatment decision in childhood. Perhaps future EAT will take place in the literature as a criterion for starting treatment in children with $\mathrm{SH}$. The increase in the number of cases with longer follow-up period may be important to support this view.

\section{References}

1. Aijaz NJ, Flaherty EM, Preston T. Neurocognitive function in children with compensated hypothyroidism: lack of short term effects on or off thyroxin. BMC Endocr Disord. 2006; 6: 2.

2. Kanaya AM, Harris F, Volpato S, Perez-Stable EJ, Harris T, Bauer DC Association between thyroid dysfunction and total cholesterol level in an older biracial population: the health, aging and body composition study. Arch Intern Med. 2002; 162: 773-779.

3. Bona G, Prodam F, Monzani A. Subclinical hypothyroidism in children: natural history and when to treat. J Clin Res Pediatr Endocrinol. 2013; 5: 23-28.

4. Rodondi N, Newman AB, Vittinghoff E, Luben RN, Satterfield S, Harris TB et al. Subclinical hypothyroidism and the risk of heart failure, other cardiovascular events, and death. Arch Intern Med. 2005; 165: 2460-2466.

5. Monzani F, Di Bello V, Caraccio N, Bertini A, Giorgi D, Giusti C, et al. Effect of levothyroxine on cardiac function and structure in subclinical hypothyroidism: a double blind, placebo-controlled study. J Clin Endocrinol Metab. 2001; 86: 1110-1115.

6. Biondi B, Cooper DS. The clinical significance of subclinical thyroid dysfunction. Endocr Rev. 2008; 29: 76-131.
7. Radetti G, Maselli M, Buzi F, Corrias A, Mussa A, Cambiaso P, et al. The natural history of the normal/mild elevated TSH serum levels in children and adolescents with Hashimoto's thyroiditis and isolated hyperthyrotropinaemia: a 3-year follow-up. Clin Endocrinol (Oxf). 2012; 76: 394-398.

8. Ergür AT, Taner Y, Ata E, Melek E, Bakar EE, Sancak T. Neurocognitive functions in children and adolescents with subclinical hypothyroidism. J Clin Res Pediatr Endocrinol. 2012; 4: 21-24.

9. lacobellis G, Ribaudo MC, Assael F, Vecci E, Tiberti C, Zappaterreno A, et al. Echocardiographic epicardial adipose tissue is related to anthropometric and clinical parameters of metabolic syndrome: a new indicator of cardiovascular risk. J Clin Endocrinol Metab. 2003; 88: 5163-5168.

10. lacobellis G, Willens HJ, Barbaro G, Sharma AM. Threshold values of high risk echocardiographic epicardial fat thickness. Obesity (Silver Spring). 2008; 16: 887-892.

11. lacobellis G, Barbaro G, Gerstein HC. Relationship of epicardial fat thickness and impaired fasting glucose. Int J Cardiol. 2008; 128: 424-426.

12. Gawlik A, Such K, Dejner A, Zachurzok A, Antosz A, Malecka-Tendera E. Subclinical hypothyroidism in children and adolescents: is it clinically relevant?. Int J Endocrinol. 2015; 691071.

13. Kong WM, Sheikh MH, Lumb PJ, Naoumova RP, Freedman DB, Crook M, et al. A 6-month randomized trial of thyroxine treatment in women with mild subclinical hypothyroidism. Am J Med. 2002; 112: 348-354.

14. Zhu DF, Wang ZX, Zhang DR, Pan ZL, He S, Hu XP, et al. FMRI revealed neural substrate for reversible working memory dysfunction in subclinical hypothyroidism. Brain. 2006; 129: 2923-2930.

15. Diez JJ. Hypothyroidism in patients older than 55 years: an analysis of the etiology and assessment of the effectiveness of therapy. J Gerontol A Biol Sci Med Sci. 2002; 57: 315-320.

16. Çatı ı, Kır M, Anık A, Yilmaz N, Böber E, Abaci A. The effect of L-thyroxine treatment on left ventricular functions in children with subclinical hypothyroidism. Archives of Disease in Childhood. 2015; 100: 130-137.

17. Rodondi N, Bauer DC, Cappola AR, Cornuz J, Robbins J, Fried LP, et al. Subclinical thyroid dysfunction, cardiac function, and the risk of heart failure. The Cardiovascular Health study. J Am Coll Cardiol. 2008; 52: 1152-1159.

18. Mao S, Wang Y, Jiang G, Zhao Z. Effects of levothyroxine therapy on left and right ventricular function in neonates with congenital hypothyroidism: a tissue Doppler echocardiography study. Eur J Pediatr. 2007; 166: 1261-1265.

19. Toscano E, Pacileo G, Limongelli G, Verrengia M, Di Mita O, Di Maio S, et al. Subclinical hypothyroidism and Down's syndrome; studies on myocardial structure and function. Arc Dis Child. 2003; 88: 1005-1008.

20. Brienza C, Grandone A, Di Salvo G, Corona AM, Di Sessa A, Pascotto C, et al. Subclinical hypothyroidism and myocardial function in obese children. Nutr Metab Cardiovasc Dis. 2013; 23: 898-902.

21. Asik M, Sahin S, Ozkul F, Anaforoglu I, Ayhan S, Karagol S, et al. Evaluation of epicardial fat tissue thickness in patients with Hashimoto thyroiditis. Clinical Endocrinology. 2013; 79: 571-576.

22. Unubol M, Eryilmaz U, Guney E, Akgullu C, Kurt Omurlu I. Epicardial adipose tissue in patients with subclinical hypothyroidism. Minerva Endocrinol. 2014; 39: $135-140$.

23. Santos OC, Silva NA, Vaisman M, Turano MD, Dytz MG, Huber GA, et al. Evaluation of epicardial fat tissue thickness as a marker of cardiovascular risk in patients with subclinical hypothyroidism. Journal of Endocrinological Investigation. 2015; 38: 421-427.

24. Korkmaz L, Sahin S, Akyüz AR, Ziyrek M, Anaforoglu I, Kose M, et al. Epicardial adipose tissue increased in patients with newly diagnosed subclinical hypothyroidism Med. Princ Pract. 2013; 22: 42-46.

25. lacobellis G, Barbaro G, Gerstein HC. Relationship of epicardial fat thickness and impaired fasting glucose. Int J Cardiol. 2008; 128: 424-426.

26. Malavazos AE, Ermetic F, Coman C, Corsi MM, Morricoone L, Ambrossi B. Influence of epicardial adipose tissue and adipocytokine levels on cardiac abnormalities in visceral obesity. Int J Cardiol. 2007; 121: 132. 
27. Aydogdu A, Karakas EY, Erkus E, Altıparmak IH, Savık E, Ulas T, et al. Epicardial fat thickness and oxidative stress parameters in patients with subclinical hypothyroidism. Arch Med Sci. 2017; 13: 383-389.

28. Aşık G, Törel Ergür A, Şanlı C. Evaluation of Epicardial Adipose Tissue Thickness in Children Detected Subclinical Hypothyroidism. 2016.

29. Farghaly HS, Metwalley KA, Raafat DM, Algowhary M, Said GM. Epicardia Fat Thickness in Children with Subclinical Hypothyroidism and Its Relationship to Subclinical Atherosclerosis: A Pilot Study. Horm Res Paediatr. 2019; 92 : 99-105.

30. Tei C, Ling LH, Hodge DO, Bailey KR, Oh JK, Rodeheffer RJ, et al. New index of combined systolic and diastolic myocardial performance: a simple and reproducible measure of cardiac function--a study in normals and dilated cardiomyopathy. J Cardiol. 1995; 26: 357-366.

31. Yazici M, Gorgulu S, Sertbas Y, Erbilen E, Albayrak S, Yildiz O, et al Effects of thyroxin therapy on cardiac function in patients with subclinical hypothyroidism: index of myocardial performance in the evaluation of left ventricular function. Int J Cardiol 2004; 95: 135-143.
32. Park JS, Ahn SG, Hwang JW, Lim HS, Choi BJ, Choi SY, et al. Impact of body mass index on the relationship of epicardial adipose tissue to metabolic syndrome and coronary artery disease in an Asian population. Cardiovasc Diabetol. 2010; 9: 29.

33. Ergür AT, Onarlığlu T, Marakoğlu K, Sezer H, Suzen B, Öktem A. Comparıson Of Body Composıtıon Parameters In Chıldren And Adolescents, Usıng Skinfold And Bıoelectrıcal Impedance Methods. Turkish J Pediatr Dis. 2012; 6: 133-138.

34. Vanderpump MP, Tunbridge WM, French JM, Appleton D, Bates D, Clark $F$, et al. The incidence of thyroid disorders in the community: a twenty-year follow-up of the Whickham Survey. Clinical endocrinology. 1995; 43: 55-68.

35. Scott JE, Kyffin TW, Morris GA. Copper tetrapyridino 'phthalocyanin' (Cuprolinic blue) differs in shape from the palladium and platinum analogues, and this affects staining of polynucleotides. Eur J Basic Appl Histochem. 1991; 35: 7-14 